Keywords: PD-L1; exosomes; circulating nucleic acids; immunotherapy; predictive biomarker; pharmacogenetics; nivolumab; pembrolizumab

\title{
PD-L1 mRNA expression in plasma-derived exosomes is associated with response to anti-PD-1 antibodies in melanoma and NSCLC
}

\author{
Marzia Del Re ${ }^{1}$, Riccardo Marconcini ${ }^{2}$, Giulia Pasquini ${ }^{2}$, Eleonora Rofi ${ }^{1}$, Caterina Vivaldi ${ }^{2}$, Francesco Bloise ${ }^{2}$, \\ Giuliana Restante ${ }^{1}$, Elena Arrigoni ${ }^{1}$, Chiara Caparello ${ }^{2}$, Maria Grazia Bianco ${ }^{2}$, Stefania Crucitta ${ }^{1}$, \\ lacopo Petrini ${ }^{3}$, Enrico Vasile ${ }^{2}$, Alfredo Falcone ${ }^{2}$ and Romano Danesi ${ }^{*}, 1$ \\ ${ }^{1}$ Clinical Pharmacology and Pharmacogenetics Unit, Department of Clinical and Experimental Medicine, University of Pisa, Pisa, \\ Italy; ${ }^{2}$ Medical Oncology Unit, Department of Translational Research and New Technologies in Medicine and Surgery, University \\ of Pisa, Pisa, Italy and ${ }^{3}$ General pathology, Department of Translational Research and New Technologies in Surgery and Medicine, \\ University of Pisa, Pisa, Italy
}

Background: PD-L1 expression in tumour tissues is widely used to select patients to receive anti-PD-1/PD-L1 antibodies, but data are lacking on the correlation of plasma PD-L1 levels with the effect of treatments.

Methods: To investigate the association between PD-L1 mRNA in plasma-derived exosomes and response to nivolumab and pembrolizumab in patients with melanoma $(n=18)$ and NSCLC $(n=8)$, blood was obtained at time point 0 and after 2 months. Exosomal PD-L1 mRNA was measured by digital droplet PCR.

Results: The mean \pm s.e.m. PD-L1 levels in patients with complete and partial responses were $830.4 \pm 231.3$ and $242.5 \pm 82.5$ copies per $\mathrm{ml}$ at time 0 vs 2 months, respectively $(P=0.016)$. In patients with stable disease the mean \pm s.e.m. values were $298.8 \pm 97.2$ vs $247.5 \pm 29.8$ copies per $\mathrm{ml}(P=0.586)$, while in progressive disease, PD-L1 mRNA levels were $204.0 \pm 68.8$ vs $416.0 \pm 87.8$ copies per $\mathrm{ml}$ at time 0 vs 2 months, respectively $(P=0.001)$.

Conclusions: This study demonstrates that exosomal PD-L1 is significantly associated with response to treatment.

Immunotherapy has substantially improved the clinical outcome of several tumours, including cancers poorly responsive to chemotherapy (Robert et al, 2015; Reck et al, 2016). PD-L1 assessment in tumour tissue (i.e., NSCLC) allows to identify a patient population with higher likelihood of response with respect to chemotherapy (Reck et al, 2016). However, changes in the activity of signal transduction patways (i.e., MAPK) (Jiang et al, 2013) may affect PD-L1 levels, thus impairing its predictive value if assessed on a single-tissue biopsy. For these reasons, the interest of the scientific community is turning towards other potential biomarkers, such as mutational load and microsatellite instability (Rizvi et al, 2015; Dudley et al, 2016). Exosomes are microvesicles actively released from cancer cells; they have a size range of 40 $150 \mathrm{~nm}$ and a lipid bilayer membrane and they carry proteins, RNA and DNA of cells from which they are originated (Kalluri, 2016). Their involvement in immune signalling, reprogramming of surrounding cells, as well as their ability to influence tumour microenvironment in favour of immune escape, therapy resistance, tumour growth and metastasis have been demonstrated (Kalluri, 2016).

For these reasons, the present study was aimed at evaluating PD-L1 mRNA expression in plasma-derived exosomes to monitor response to the anti-PD-1 agents nivolumab and pembrolizumab in melanoma and NSCLC.

*Correspondence: R Danesi; E-mail: romano.danesi@unipi.it

Received 18 December 2017; revised 2 February 2018; accepted 12 February 2018; published online 6 March 2018

(C) 2018 Cancer Research UK. All rights reserved 0007 - 0920/18 


\section{PATIENTS AND METHODS}

Patients. Patients affected by locally advanced or metastatic melanoma or NSCLC given nivolumab ( $240 \mathrm{mg}$ i.v. every 2 weeks) or pembrolizumab (200 mg i.v. every 3 weeks) as per approved schedule were enroled. The experimental part of the study

Table 1. Clinical characteristics of patients

\begin{tabular}{|c|c|c|}
\hline & $\begin{array}{l}\text { Melanoma } \\
\quad(n=18)\end{array}$ & $\begin{array}{l}\text { NSCLC } \\
(n=8)\end{array}$ \\
\hline $\begin{array}{l}\text { Age } \\
\text { Median (range) }\end{array}$ & $71(45-87)$ & $64(52-77)$ \\
\hline $\begin{array}{l}\text { Gender } \\
\quad \text { Male/female }\end{array}$ & $12 / 6$ & $5 / 3$ \\
\hline $\begin{array}{c}\text { ECOG PS } \\
0 / 1-2\end{array}$ & $10 / 8$ & $5 / 3$ \\
\hline $\begin{array}{l}\text { Tumour type } \\
\text { Squamous/adenocarcinoma }\end{array}$ & & $1 / 7$ \\
\hline $\begin{array}{l}\text { BRAF mutation } \\
\text { Yes/no }\end{array}$ & $5 / 13$ & \\
\hline $\begin{array}{l}\text { EGFR mutation } \\
\text { Yes/no }\end{array}$ & & $1 / 7$ \\
\hline $\begin{array}{l}\text { ALK translocation } \\
\text { Yes/no }\end{array}$ & & $0 / 8$ \\
\hline First line immunotherapy & $11 / 18$ & $0 / 8$ \\
\hline \multicolumn{3}{|c|}{$\begin{array}{l}\text { Abbreviations: } \mathrm{ALK}=\text { anaplastic lymphoma kinase; } \mathrm{BRAF}=\mathrm{v}-\mathrm{RAF} \text { murine sarcoma vira } \\
\text { oncogene homolog } \mathrm{B} 1 ; \mathrm{ECOG} \mathrm{PS}=\text { Eastern Cooperative Oncology Group performanc } \\
\text { status; } \mathrm{EGFR}=\text { epidermal growth factor receptor; } \mathrm{NSCLC}=\text { non-small cell lung cancer. }\end{array}$} \\
\hline
\end{tabular}

consisted of two blood drawings from each patient for the measurement of exosomal mRNA levels of PD-L1 at time 0 (baseline) and at the time of radiological assessment of disease status, i.e., after 2 months of treatment. Complete or partial responses (CR, PR), disease stabilisation (SD) and disease progression (PD) were defined following RECIST (v. 1.1) criteria.

Measurement of exosomal PD-L1. A blood sample of $6 \mathrm{ml}$ was collected in EDTA tubes and centrifuged for $10 \mathrm{~min}$ at $1900 \mathrm{~g}$ within 2 hours. The isolation of exosomes from plasma and extraction of RNA was previously described (Del Re et al, 2017) and performed using the exoRNeasy kit (Qiagen, Valencia, CA). The analysis of PD-L1 mRNA was performed by the QX100 ddPCR (Bio-Rad, Hercules, CA, USA) using the One-Step RTddPCR kit. The PrimePCR ddPCR Expression Probe Assay for CD274 (human) was used to assess PD-L1 expression and the human $\beta$-actin ddPCR assay was used as internal control. Fluorescence signal quantification was performed by the droplet reader and the QuantaSoft software (Bio-Rad). The ratio of positive $v s$ negative droplets was used to determine the number of mRNA copies per $\mathrm{ml}$ of the target molecule in the input reaction. Droplets with a fluorescence intensity threshold higher than 4000 were considered positive. Each plasma sample was extracted once and triplicate ddPCR analyses were performed per sample. The values reported below (copies per $\mathrm{ml}$ ) represent the mean of the triplicate.

Statistical analysis. Inferential statistics was used to assess the significance of differences between paired samples (PD-L1 levels at time 0 vs 2 months; paired $t$-test) and unpaired groups (time 0 $\mathrm{PR}+\mathrm{CR} v s \mathrm{SD}+\mathrm{PD}$; unpaired $t$-test); the significance level was set

Table 2. PD-L1 copies per $\mathrm{ml}$ in plasma-derived exosomes vs tumour response in patients treated with pembrolizumab or nivolumab for melanoma or NSCLC

\begin{tabular}{|c|c|c|c|c|c|}
\hline Patient & Tumour type & Treatment & PD-L1 time 0 (copies per $\mathrm{ml}$ ) & PD-L1 2 months (copies per ml) & Response \\
\hline 1 & Melanoma & Nivolumab & 500 & 240 & CR \\
\hline $2^{a}$ & Melanoma & Pembrolizumab & 2000 & 1000 & CR \\
\hline 3 & Melanoma & Pembrolizumab & 140 & 70 & PR \\
\hline 4 & Melanoma & Pembrolizumab & 2500 & 0 & PR \\
\hline 5 & Melanoma & Pembrolizumab & 180 & 220 & PR \\
\hline 6 & Melanoma & Pembrolizumab & 1045 & 520 & PR \\
\hline 7 & Melanoma & Pembrolizumab & 215 & 80 & PR \\
\hline 8 & Melanoma & Pembrolizumab & 600 & 80 & PR \\
\hline 9 & Melanoma & Pembrolizumab & 405 & 0 & PR \\
\hline 10 & Melanoma & Pembrolizumab & 350 & 100 & PR \\
\hline 11 & NSCLC & Nivolumab & 1700 & 400 & PR \\
\hline 12 & NSCLC & Nivolumab & 330 & 200 & PR \\
\hline Mean \pm s.e.m. & & & $830.4 \pm 231.3$ & $242.5 \pm 82.5$ & $P=0.016$ \\
\hline 13 & Melanoma & Pembrolizumab & 190 & 160 & $\mathrm{SD}$ \\
\hline 14 & Melanoma & Pembrolizumab & 95 & 260 & SD \\
\hline 15 & NSCLC & Nivolumab & 380 & 280 & $\mathrm{SD}$ \\
\hline 16 & NSCLC & Nivolumab & 530 & 290 & SD \\
\hline Mean \pm s.e.m. & & & $298.8 \pm 97.2$ & $247.5 \pm 29.8$ & $P=0.586$ \\
\hline $17^{b}$ & Melanoma & Pembrolizumab & 90 & 360 & PD \\
\hline 20 & Melanoma & Pembrolizumab & 90 & 200 & PD \\
\hline 21 & Melanoma & Pembrolizumab & 0 & 140 & PD \\
\hline 22 & Melanoma & Pembrolizumab & 70 & 500 & PD \\
\hline 18 & Melanoma & Nivolumab & 115 & 210 & PD \\
\hline 19 & Melanoma & Nivolumab & 495 & 550 & PD \\
\hline 23 & NSCLC & Nivolumab & 270 & 700 & PD \\
\hline 24 & NSCLC & Nivolumab & 0 & 140 & PD \\
\hline 25 & NSCLC & Nivolumab & 260 & 360 & PD \\
\hline $26^{\mathrm{b}}$ & NSCLC & Nivolumab & 650 & 1000 & PD \\
\hline Mean \pm s.e.m. & & & $204.0 \pm 68.8$ & $416.0 \pm 87.8$ & $P=0.001$ \\
\hline \multicolumn{6}{|c|}{$\begin{array}{l}\text { Abbreviations: } C R=\text { complete response; } \mathrm{NSCLC}=\text { non-small cell lung cancer; } \mathrm{PD}=\text { progression of disease; } \mathrm{PR}=\text { partial response; } \mathrm{SD}=\text { stable disease. Patients were grouped on the basis of } \\
\text { tumour response and mean } \pm \text { s.e. } \mathrm{m} \text {. values of PD-L1 copies per } \mathrm{ml} \text { are reported; } P \text {-values were calculated by paired } t \text {-test. } \\
{ }^{\mathrm{a}} \text { Death due to acute myocardial infarction. } \\
{ }^{b} \text { Death due to PD. }\end{array}$} \\
\hline
\end{tabular}


A

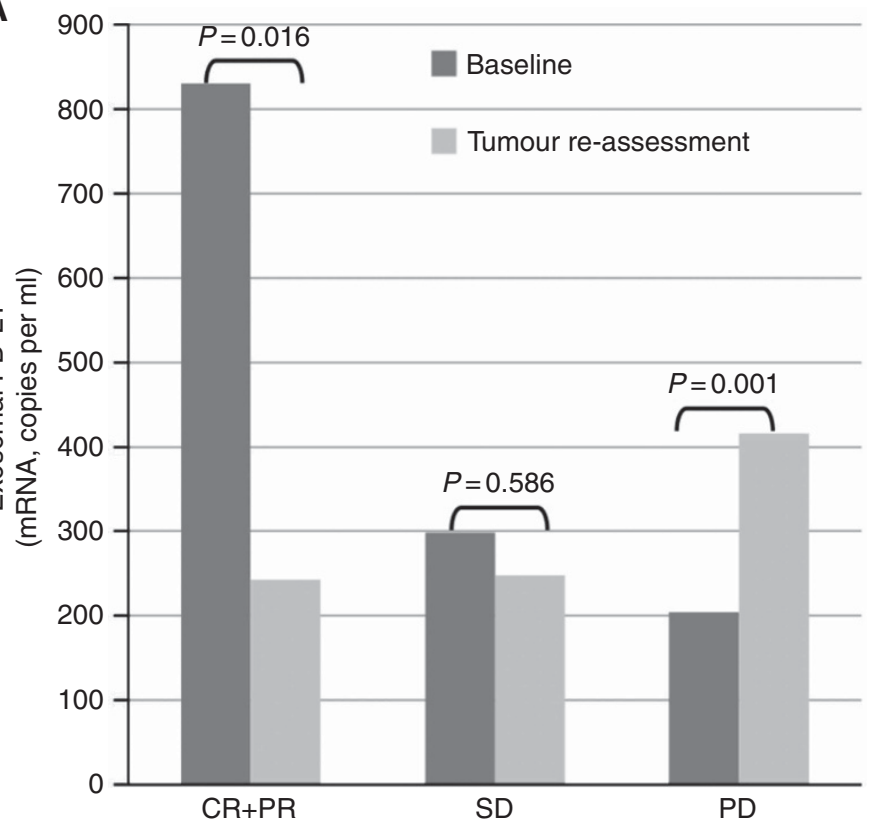

B
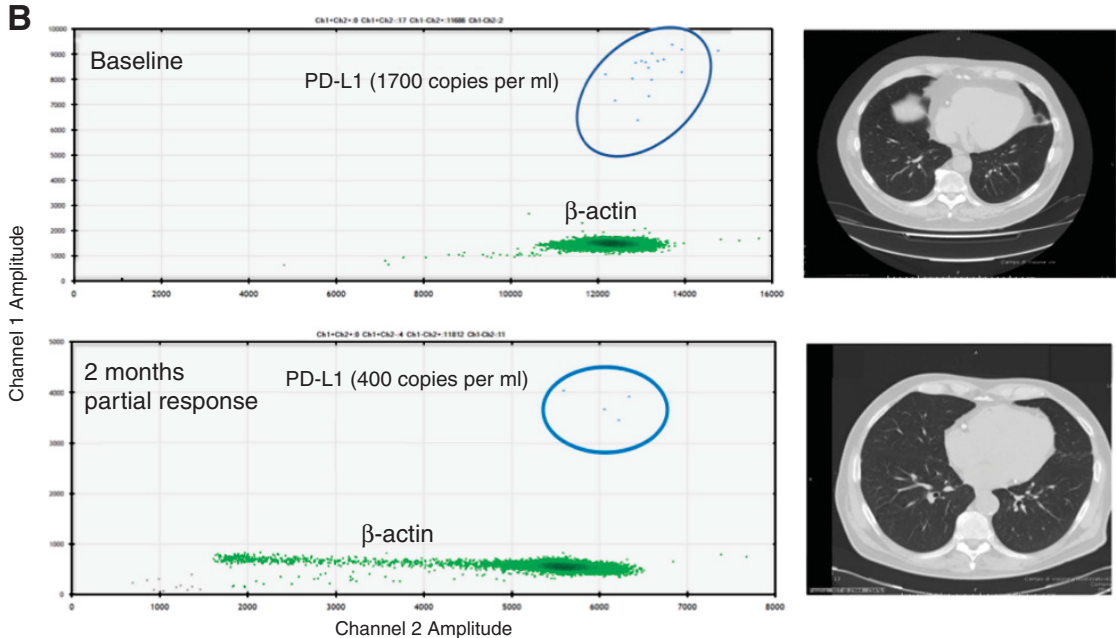

C

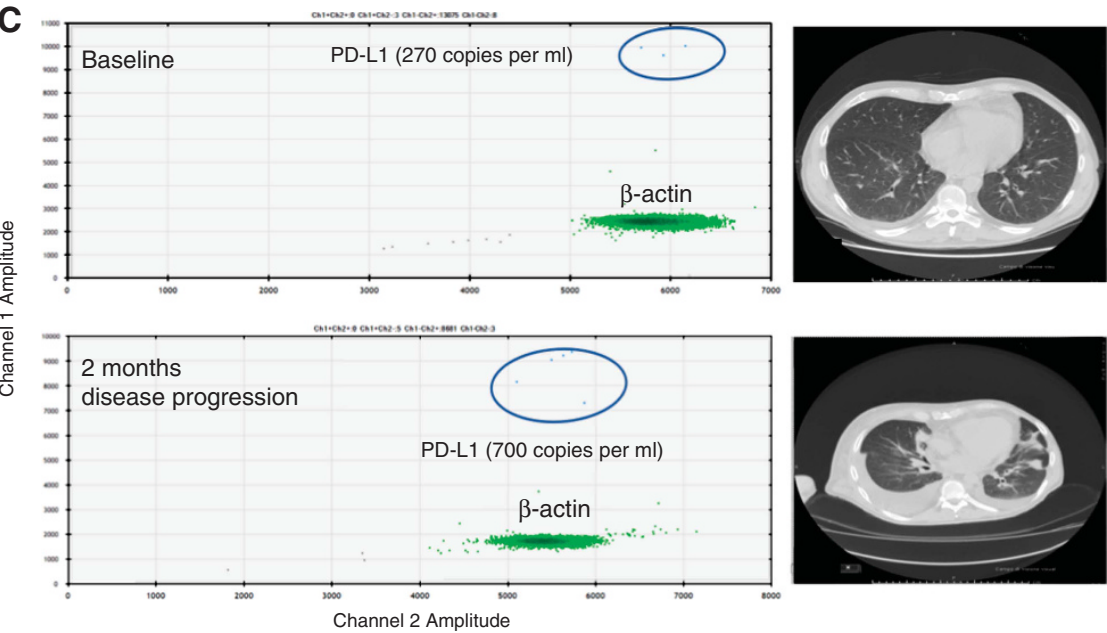

Figure 1. Effect of treatment with anti-PD-1 antibodies on exosomal PD-L1 expression and clinical response in NSCLC and melanoma. (A) Mean values of PD-L1 (copies per $\mathrm{ml}$ ) evaluated in baseline (time 0, dark grey) and at tumour re-assessment after 2 months of treatment (light grey) in patients grouped according to tumour response (CR + PR, SD and PD); P-values are reported on top of the columns. ddPCR plots (B and C) showing PD-L1 exosomal mRNA variations during the follow up of 2 non-small cell lung cancer patients. The blue dots circled in blue represent PD-L1, whereas the green dots represent B-actin. (B) PD-L1 expression at the time of patient entry into the study (1700 copies per ml) and reduction after 2 months (400 copies per $\mathrm{ml}$ ); the patient showed a partial response. (C) detection of PD-L1 expression at baseline (270 copies per $\mathrm{ml}$ ) and increase after 2 months (700 copies per $\mathrm{ml}$ ); the subject had disease progression. $\mathrm{CR}=$ complete response; $\mathrm{PD}=$ progression of disease; $\mathrm{PR}=$ partial response; $\mathrm{SD}=$ stable disease. 
at 5\%. The GraphPad software (GraphPad Software, La Jolla, CA, USA online version) was used for statistical calculations.

\section{RESULTS}

Eighteen patients with melanoma were enroled (Table 1); there were $2 \mathrm{CR}, 8 \mathrm{PR}, 2 \mathrm{SD}$ and $6 \mathrm{PD}$. The number of mRNA copies per $\mathrm{ml}$ of PD-L1 in plasma-derived exosomes decreased in patients with CR/PR (mean 793.5 vs 231, time 0 vs 2 months, respectively), while it increased in patients with PD (mean 143.3 vs 326.7, time 0 vs 2 months, respectively). Two patients died, one due to $\mathrm{PD}$ (mRNA PD-L1 copies per $\mathrm{ml}$ increased from 90 to 360), and the other because of acute myocardial infarction, while on CR (PD-L1 mRNA decreased from 2000 to 1000 copies per ml). Table 2 reports a detailed description of PD-L1 changes.

Patients 4 and 9 reported a PR during treatment with pembrolizumab; perhaps unexpectedly, PD-L1 was undetectable in plasma at tumour re-assessment. However, exosomal $B$-actin mRNA was detectable in these two patients $\left(8.1\right.$ and $9.0 \times 10^{6}$ copies per $\mathrm{ml}$, respectively), thus excluding a false negative result.

Eight patients with NSCLC were enroled in the study (Table 1); there were $2 \mathrm{PR}, 2 \mathrm{SD}$ and $4 \mathrm{PD}$. The mRNA copies per $\mathrm{ml}$ of PDL1 were correlated with tumour response, with a clear increase in patients with PD (mean, 295 vs 550 copies per ml, time 0 vs 2 months, respectively) and decrease in patients who achieved a PR (mean, 1015 vs 300 copies per ml, time 0 vs 2 months, respectively). A modest variation was seen in patients with SD (mean 455 vs 285, time 0 vs 2 months, respectively) (Table 2). Figure 1 reports the data of 2 representative patients with NSCLC showing a PR and a $\mathrm{PD}$; PD-L1 plasma levels varied in accordance with disease response or progression.

In the overall population, the difference between PD-L1 mRNA copies per $\mathrm{ml}$ was significant both in patients with $\mathrm{CR}+\mathrm{PR}$ (830.4 \pm 231.3 at time 0 vs $242.5 \pm 82.5$ after 2 months, $P=0.016)$ and with $\mathrm{PD}(204.0 \pm 68.8$ vs $416.0 \pm 87.8$, time 0 vs 2 months thereafter, $P=0.001$ ), but not, as expected, in patients with SD (298.8 \pm 97.2 at time 0 vs $247.5 \pm 29.8$ after 2 months, $P=0.586$; Table 2). At time 0 , subjects with $\mathrm{CR}$ and $\mathrm{PR}$ showed a significantly higher number of copies per $\mathrm{ml}$ of PD-L1 mRNA compared to subjects with SD and PD $(830.4 \pm 231.3$ vs $231.1 \pm 55.7, P=0.012$; Table 2$)$.

\section{DISCUSSION}

This study first demonstrates exosomal PD-L1 expression changes during treatment with anti-PD-1 antibodies. Furthermore, the results show that PD-L1 levels in plasma-derived exosomes significantly decreased in patients responding to treatment and increased in subjects with disease progression, while, as expected, no significant changes were observed in patients with SD.

The issue of variability of PD-L1 expression in relation to its predictive role has been addressed in tissue biopsies collected in the same patients at different time-points (Cho et al, 2017). The predictive role of $\mathrm{PD}-\mathrm{L} 1$ expression in tumour tissue is still a matter of debate, since cancers with low expression of PD-L1 may respond to nivolumab and survival is longer than patients treated with chemotherapy (Borghaei et al, 2015). Moreover, it is not known which effect other therapies, including chemotherapy and radiotherapy, may have on $\mathrm{PD}-\mathrm{L} 1$ expression. Thus, its assessment in primary tumour at the time of diagnosis may not inform on changes which will occur during clonal evolution and selective pressure of treatments. Studies on circulating biomarkers are increasing in number because they can provide important information on dynamic response to treatment. Although they are not aimed at selecting patients for the administration of anti-
PD-1/PD-L1 treatments, they have the potential to provide relevant information on clinical outcome. The assessment of PDL1 expression in circulating tumour cells has been evaluated in bladder cancer and NSCLC for its potential capability to guide the selection of patients to be treated with anti-PD-1 or PD-L1 antibodies (Anantharaman et al, 2016; Nicolazzo et al, 2016). Other studies evaluating tumour mutational burden or microsatellite instability may also be suitable to personalise treatment, although they follow a different strategy and PD-L1 expression is not specifically addressed (Rizvi et al, 2015; Dudley et al, 2016).

The strategy of using exosomes in this study was suggested by their ability to preserve intact mRNA. Exosomes have an intriguing role in cancer signalling and immunity; they are involved in cell-to-cell communication, they reflect changes induced by treatment and, most importantly, they are involved in immune escape (Liu et al, 2015). The ability of exosomes to communicate inhibitory signals to effector cells, including NK, macrophages, dendritic cells and T cells, may explain why the decline of PD-L1 in responding patients is associated with tumour response and possibly a restoration of cellular immunity. To confirm this hypothesis, larger cohorts of patients will be required, as well as a comparison of PD-L1 expression in paired tissue and plasmaderived exosomes.

In conclusion, the present work demonstrates in a limited population that dynamic measurement of PD-L1 expression in plasma-derived exosomes is feasible and may provide useful information on the response to treatment with anti-PD-1 antibodies.

\section{ACKNOWLEDGEMENTS}

This work was supported by the Fondazione Cassa Risparmio di Lucca (Lucca Italy) and the University of Pisa (Italy) to Romano Danesi.

\section{CONFLICT OF INTEREST}

The authors declare no conflict of interest.

AUTHOR CONTRIBUTIONS

Conception and design: MDR, RD. Development of methodology: MDR, ER, EA, GR and SC. Clinical protocols/amendments: MDR, RD, ER. Acquisition of data: MDR, RM, GP, ER, CV, FB, GR, EA, CC, MGB, SC, IP, EV, AF and RD. Analysis and interpretation of data: MDR, ER, EA and RD. Writing, review and/or revision of the manuscript: All authors. Administrative, technical or material support: MDR, RM, GP, ER, CV, FB, EA and MGB. Study supervision: RD, IP, EV and AF.

\section{DISCLAIMER}

This work was approved by the Ethics Committee of the Area Vasta Nord-Ovest Toscana (Italy) in accordance with the principles of the Declaration of Helsinki.

\section{REFERENCES}

Anantharaman A, Friedlander T, Lu D, Krupa R, Premasekharan G, Hough J, Edwards M, Paz R, Lindquist K, Graf R, Jendrisak A, Louw J, Dugan L, Baird S, Wang Y, Dittamore R, Paris PL (2016) Programmed death-ligand 1 (PD-L1) characterization of circulating tumor cells (CTCs) in muscle invasive and metastatic bladder cancer patients. BMC Cancer 16: 744 . 
Borghaei H, Paz-Ares L, Horn L, Spigel DR, Steins M, Ready NE, Chow LQ, Vokes EE, Felip E, Holgado E, Barlesi F, Kohlhaufl M, Arrieta O, Burgio MA, Fayette J, Lena H, Poddubskaya E, Gerber DE, Gettinger SN, Rudin CM, Rizvi N, Crino L, Blumenschein Jr. GR, Antonia SJ, Dorange C, Harbison CT, Graf Finckenstein F, Brahmer JR (2015) Nivolumab versus docetaxel in advanced nonsquamous non-small-cell lung cancer. $N$ Engl $J$ Med 373: 1627-1639.

Cho JH, Sorensen SF, Choi YL, Feng Y, Kim TE, Choi H, Georgsen JB, DolledFilhart M, Emancipator K, Meldgaard P, Sun JM, Kim HK, Choi YS, Shim YM, Zhou W, Hager H, Kim J (2017) Programmed death ligand 1 expression in paired non-small cell lung cancer tumor samples. Clin Lung Cancer 18: e473-e479.

Del Re M, Biasco E, Crucitta S, Derosa L, Rofi E, Orlandini C, Miccoli M, Galli L, Falcone A, Jenster GW, van Schaik RH, Danesi R (2017) The detection of androgen receptor splice variant 7 in plasma-derived exosomal rna strongly predicts resistance to hormonal therapy in metastatic prostate cancer patients. Eur Urol 71: 680-687.

Dudley JC, Lin MT, Le DT, Eshleman JR (2016) Microsatellite instability as a biomarker for PD-1 blockade. Clin Cancer Res 22: 813-820.

Jiang X, Zhou J, Giobbie-Hurder A, Wargo J, Hodi FS (2013) The activation of MAPK in melanoma cells resistant to BRAF inhibition promotes PD-L1 expression that is reversible by MEK and PI3K inhibition. Clin Cancer Res 19: 598-609.

Kalluri R (2016) The biology and function of exosomes in cancer. J Clin Invest 126: $1208-1215$.

Liu Y, Gu Y, Cao X (2015) The exosomes in tumor immunity. Oncoimmunology 4: e1027472.

Nicolazzo C, Raimondi C, Mancini M, Caponnetto S, Gradilone A, Gandini O, Mastromartino M, Del Bene G, Prete A, Longo F, Cortesi E, Gazzaniga P (2016) Monitoring PD-L1 positive circulating tumor cells in non-small cell lung cancer patients treated with the PD-1 inhibitor Nivolumab. Sci Rep 6: 31726.

Reck M, Rodriguez-Abreu D, Robinson AG, Hui R, Csoszi T, Fulop A, Gottfried M, Peled N, Tafreshi A, Cuffe S, O’Brien M, Rao S, Hotta K, Leiby MA, Lubiniecki GM, Shentu Y, Rangwala R, Brahmer JR. Investigators K (2016) Pembrolizumab versus chemotherapy for PD-L1-positive non-small-cell lung cancer. N Engl J Med 375: 1823-1833.

Rizvi NA, Hellmann MD, Snyder A, Kvistborg P, Makarov V, Havel JJ, Lee W, Yuan J, Wong P, Ho TS, Miller ML, Rekhtman N, Moreira AL, Ibrahim F, Bruggeman C, Gasmi B, Zappasodi R, Maeda Y, Sander C, Garon EB, Merghoub T, Wolchok JD, Schumacher TN, Chan TA (2015) Cancer immunology. Mutational landscape determines sensitivity to PD-1 blockade in non-small cell lung cancer. Science 348: $124-128$.

Robert C, Long GV, Brady B, Dutriaux C, Maio M, Mortier L, Hassel JC, Rutkowski P, McNeil C, Kalinka-Warzocha E, Savage KJ, Hernberg MM, Lebbe C, Charles J, Mihalcioiu C, Chiarion-Sileni V, Mauch C, Cognetti F, Arance A, Schmidt H, Schadendorf D, Gogas H, Lundgren-Eriksson L, Horak C, Sharkey B, Waxman IM, Atkinson V, Ascierto PA (2015) Nivolumab in previously untreated melanoma without BRAF mutation. $N$ Engl J Med 372: 320-330.

This work is published under the standard license to publish agreement. After 12 months the work will become freely available and the license terms will switch to a Creative Commons AttributionNonCommercial-Share Alike 4.0 Unported License. 